УДК 008

DOI: $10.17223 / 22220836 / 29 / 14$

\title{
В.В. Харитон
}

\section{К ВОПРОСУ РАЙОНИРОВАНИЯ ВОСТОЧНОЙ ЕВРОПЫ КАК ТУРИСТСКОГО РЕГИОНА В КОНЦЕ ХХ - НАЧАЛЕ ХХI В.}

\begin{abstract}
В настоящее время туризм - одна из крупнейших отраслей промышленности в мире. Туристическая индустрия очень конкурентоспособна, и туроператоры находятся под увеличиваюшимся давлением. В связи с этой тенденцией пристальное внимание уделяется разнообразным направлениям туристических потоков, в том числе и в странах Восточной Европь.

Данная статья посвящена обобщению опыта туризма в Восточноевропейском регионе на современном этапе развития общества. В статье изучены вопросы районирования Европы, специфики развития туризма в странах туристического региона Восточной Европь, а также проблемы развития туризма в данном регионе в коние XXначале XXI в. В статье освещена проблема регионализаџии Европь, которая сегодня является спорной. Широкую популярность получила классификация туристических зон мира, предложенная ВТО. Также в статье рассматриваются классификаиии системы туристского зонирования, предложенные исследователями Ю.Д. Дмитриевским, А.Г. Манаковым. Помимо прочего, в статье рассматриваются подходы к районированию Республики Беларусь, опираясь на культурно-географическое районирование мира. Анализ показывает перспективы туристического бизнеса в Восточной Европе. Республика Беларусь как одна из стран этого региона имеет несомненньй туристический потенциал.

Ключевые слова: Восточная Европа, туристский регион, районирование, культурноисторический подход.
\end{abstract}

В XXI в. туризм является одной из наиболее развивающихся отраслей во всем мире. Туристская индустрия в 2015 г. создала 284 млн рабочих мест, что составляет 9,5\% от мировой занятости. По результатам исследования Всемирной туристской организации при ОOH (UNWTO), количество международных туристских путешествий в 2015 г. увеличилось на 4,4 \% - до 1,184 млрд [1].

Каждый туристский регион, в том числе и страны Восточной Европы, имеет свою специфику в рамках оказания туристских услуг. В первую очередь, необходимо определить границы Восточной Европы как туристского региона.

Вопрос о регионализации Европы является дискуссионным. Перейдем к особенностям районирования Европы в туризме. Широкой известностью пользуется классификация туристских районов мира, предложенная ВТО. В основу данной классификации положены следующие факторы: социальноэкономическое развитие; рекреационный потенциал; развитие социальной инфраструктуры; географическое положение и особенности транспортного сообщения с другими странами. Согласно классификации ВТО можно выделить 6 туристских регионов [1]:

1. Европейский макрорегион: Западная, Северная, Южная, Центральная и Восточная Европа.

2. Ближневосточный макрорегион: Западная и Юго-Западная Азия, Египет и Ливия. 
3. Азиатско-Тихоокеанский макрорегион: Юго-Восточная и Восточная Азия, Австралия и Океания.

4. Южно-Азиатский макрорегион: Центральная и Южная Азия.

5. Африканский макрорегион: Африка (за исключением Египта и Ливии).

6. Американский макрорегион: Северная, Южная, Центральная Америка, островные государства и территории Карибского бассейна.

Достоинством данной классификации является четкое разделение стран мира на макрорегионы по туристскому потенциалу.

Однако считаем, что данная классификация характеризуется рядом недостатков. В первую очередь, существует несоответствие принадлежности некоторых стран к определенному региону. В качестве примера можно привести Америку, которая предполагает рассмотрение в трех регионах: Северная Америка, Латинская Америка, Карибский бассейн. В выделении туристических регионов Африки и Азии также отмечается недостаток единства. Кроме того, классификация недостаточно подробно указывает, какие именно страны входят в состав определенного макрорегиона, что обусловливает недостаточно подробное классифицирование.

Еще одной известной классификацией является система туристского районирования, предложенная исследователем Ю.Д. Дмитриевским [2], который предложил иерархию туристских районов: туристско-рекреационная зона; туристский макрорайон; туристский мезорайон; туристский микрорайон.

Согласно вышерассмотренной классификации к туристическому региону Восточной Европы относятся:

1) Балтия;

2) Польша;

3) Центральный макрорайон;

4) Причерноморский макрорайон.

Несомненным достоинством классификации Ю.Д. Дмитриевского является, в первую очередь, иерархизированность туристических регионов. С помощью разделения на туристско-рекреационные зоны, которые в свою очередь подразделяются на более мелкие сегменты, данному ученому удалось максимально подробно сегментировать мировой туризм. Однако, полагаем, что к недостаткам данного подхода можно отнести приоритет рекреационных услуг, а не культурно-исторического наследия. Тем самым в значительной степени ограничивается область использования этой классификации: правомерно руководствоваться таким сегментированием стран при анализе рекреационного туризма. Изучение специфики культурного туризма и сегментирования мира с данной позиции требует иного подхода.

Крайне важен существующий культурно-ландшафтный подход к выделению туристических регионов мира. Ключевым понятием данного подхода является термин «культурный ландшафт». С позиции советской школы культурный ландшафт понимается как антропогенный ландшафт, который был целенаправленно сформирован с учетом исторической адаптации к природным условиям под влиянием воздействия человека. Сторонники гуманитарного подхода [3-5] понимают под культурным ландшафтом культурноприродную территорию, которая возникла в результате длительного воздействия человека с природой и представляет собой устойчивую связь природных и культурных компонентов. С точки зрения экономико-географического 
подхода культурный ландшафт представляет собой культурно-хозяйственный территориальный комплекс, образовавшийся в результате воздействия хозяйственной деятельности на природу под влиянием исторических, этнокультурных и экономических факторов. Нами культурный ландшафт понимается как сложный комплекс, включающий в себя природную и культурную составляющие, которые взаимообусловлены и взаимосвязаны. На основе понятия «культурный ландшафт» можно выделять туристические регионы с позиции культурно-ландшафтного районирования.

Как отмечает А.А. Андреев [6], ландшафт образуется под влиянием двух основных факторов: природного и антропогенного. Эти факторы вступают в определенное взаимодействие, в результате которого образуется два пути развития ландшафта. При гармоничном взаимодействии природного и антропогенного факторов образуется культурный ландшафт. При чрезмерном доминировании антропогенного фактора происходит разрушение природного ландшафта, что в конечном счете приводит к образованию деструктивного ландшафта.

Среди белорусских исследователей, которые являются сторонниками культурно-ландшафтного районирования, можно выделить работы С.А. Заруцкого [7], занимающегося проблемой районирования нашей страны. Как отмечает этот исследователь, основой выделения культурно-ландшафтных районов является этнокультура населения в совокупности с природными условиями; основой выделения подрайонов - транспортно-коммуникационные связи и историко-культурный потенциал; основой выявления микрорайонов - общности историко-культурного населения, специфика сельскохозяйственной деятельности и единство ландшафта.

Геокультурный подход (историко-культурное районирование) в качестве основы использует такие факторы, как религия населения в историческом контексте; этнические особенности населения, в том числе и языки; история народа; культурное наследие; природные особенности территории [8]. По мнению В.Н. Стрелецкого [9], к факторам, определяющим районы, относятся: региональное сознание населения, его этническая и диалектическая специфика, особенности духовной и материальной культуры; поселенческая структура и специфика взаимодействия человека с природой.

Ярким представителем историко-культурного районирования является российский исследователь А.Г. Манаков. Данный исследователь предлагает использование 6 единиц для классификации туристических регионов мира [10]:

1) макрорегион;

2) мезорегион;

3) микрорегион;

4) макрорайон;

5) мезорайон;

6) микрорайон.

А.Г. Манаков выделил 10 туристских макрорегионов мира и 46 мезорегионов. Проанализируем Восточную Европу как туристический регион согласно классификации А.Г. Манакова:

1) Макрорегион - Зарубежная Европа.

2) Мезорегион - Центральная и Восточная Европа.

3) Микрорегион - Восточноевропейский туристский микрорегион (Молдавия, Украина и Беларусь). 
Следовательно, в рамках геокультурного подхода и концепции А.Г. Манакова Восточная Европа как туристический регион включает в себя 3 страны [10]:

1) Молдавию;

2) Украину;

3) Беларусь.

Среди белорусских исследователей, являющихся приверженцами культурно-исторического районирования, можно отметить труды А.А. Смолича. Данный исследователь выделил культурно-исторические районы Республики Беларусь, что позволило составить карту районирования нашей страны [11].

Ярчайшим белорусским представителем культурно-географического районирования мира является И.Н. Шарухо [12]. Учитывая всю совокупность районообразующих признаков и факторов районирования, данный исследователь выделил 19 интегральных культурно-географических районов Республики Беларусь (КГР): Полоцкая земля, Витебское Подвинье, Подисенье, Вилейщина, Гродненское Понёманье, Новогрудская земля, Верхнее Понёманье, Минская земля, Борисовская земля, Слуцкая земля, Бобруйская земля, Оршанское Поднепровье, Могилёвское Поднепровье, Мстиславско-Кричевская земля, Брестское Полесье, Пинское Полесье, Туровская земля, Припятское Полесье, Гомельское Полесье.

В XXIв. туристический потенциал Восточноевропейского региона активно развивается. Это утверждение находит отражение в многочисленных трудах отечественных и зарубежных исследователей.

В своем диссертационном исследовании А.П. Никогосян [13] выделяет Европейский регион в качестве наиболее посещаемого туристического сектора в мире. Это детерминировано вариативностью предоставления туристических услуг, а также относительно невысокими ценами на туризм в данном секторе. Сходного мнения придерживается и В.А. Набедрик [14], отметившая доминирующую роль туристического сектора Центрально-Восточной Европы на примере лечебного туризма.

Анализируя особенности туристического брендинга стран Восточной Европы, зарубежный исследователь Д. Холл [15] отмечает, что существует три основных ограничения, затрудняющих продвижение данных стран на мировом туристическом рынке. В первую очередь, это недостаток финансирования маркетингового продвижения страны на мировом туристическом рынке, что в значительной степени усугублено недостатком опыта работы на международном туристическом рынке у стран Восточной Европы. Вовторых, это стремление стран Восточноевропейского региона к получению немедленных результатов, которые могут оказаться непрочными, так как для создания сильного туристического бренда необходимы достаточно большое количество времени и длительное финансирование. Третьей проблемой является наличие централизованных, а также частично авторитарных режимов в странах Восточной Европы, что затрудняет брендинг данных стран по сравнению со странами с развитой рыночной экономикой.

Необходимо также отметить, что после распада СССР страны Восточной Европы столкнулись с тем, что их национальный туристический продукт не мог в полной мере конкурировать с туристическими ресурсами стран западного мира. В настоящее время ситуация значительно меняется за счет разработки проблем туризма на государственном уровне. 
Однако необходимо отметить, что во многих современных исследованиях развитие туризма в странах Восточной Европы по сей день оценивается как более низкое по сравнению с Западноевропейским регионом. В то же время большинство исследователей отмечают большой потенциал современной Восточной Европы как туристического региона. К примеру, О.В. Шувалова [16] говорит о том, что предпосылками роста туризма в странах Восточной Европы выступают развитая инфраструктура, невысокая стоимость туристических услуг и богатая история и культурное наследие стран Восточной Европы.

Республика Беларусь является страной с богатейшим потенциалом, способным привлечь множество туристов. По данным Министерства статистики и анализа Республики Беларусь, в стране в последние годы произошли значительные перемены в области туристической инфраструктуры. Так, в 2013 г. Республику Беларусь посетили 6240,4 тыс. иностранных граждан (из них 4 100,2 тыс. граждан СНГ), в то время как в 2012 г. их количество составило 6 127,5 тыс. человек (из них 3 881,9 тыс. граждан СНГ) [17]. Численность организованных туристов, прибывших в республику в 2014 г., составила 137,4 тыс. человек, что на 0,5 \% больше, чем в 2013 г. Из стран СНГ прибыло 115,6 тыс. человек (на 1,3 \% больше уровня 2013 г.). Лидирующие позиции среди стран Содружества по организованным туристам сохранились за Россией - 113,2 тыс. человек (увеличение на 1,7\% по сравнению с 2013 г.) и Украиной - 1,8 тыс. человек (по сравнению с 2013 г. уменьшение на 10,3 \%). В 2015 г. число посетивших Республику Беларусь составило 276260 человек, из них туристов - 91528 человек [17]. Это свидетельствует о положительной динамике развития въездного туризма в стране.

Однако сегодня в Республике Беларусь остаются следующие нерешенные проблемы в развитии туризма:

- отсутствие единой, общепризнанной в стране методики оценки рынка, а также полной статистической отчетности о потоках туристов по республике и регионам;

- недостаток уровня комфорта средств размещения туристов согласно международным стандартам;

- недостаточный уровень инвестирования в сферу туризма от государства и частных лиц;

- отсутствие системы единого научного и информационного обеспечения туристического продукта в рамках въездного и выездного туризма.

И это все при росте конкуренции на туристических рынках сопредельных стран СНГ, Балтии и Европы.

Проведенный анализ свидетельствует о перспективности туристского бизнеса в странах Восточной Европы. Республика Беларусь как одна из стран этого региона обладает несомненным туристическим потенциалом. И несмотря на то, что в настоящее время страна не играет значительной роли на международном туристском рынке, активные действия со стороны государства, в частности, активная работа в направлении привлечения инвестиций в отрасль, реставрация объектов культурно-исторического наследия, говорят о серьезной работе в данном направлении. Все это вкупе позволит занять Республике Беларусь свою нишу не только в Восточноевропейском регионе, но и на международной туристской арене. 


\section{Литература}

1. World Trade Organization [Электронный pecypc]. URL: https://www.wto.org. (дата обращения: 16.11.2016).

2. Дмитриевский Ю.Д. Туристские районы мира. Смоленск: СГУ, 2000. 224 с.

3. Герасимов A.C. Подходы к исследованию региональной идентичности в отечественной науке // Вестник Псковского государственного университета. Естественные и физико-математические науки. 2013. Вып. 3. С. 57-63.

4. Иванова Л.В. Историко-культурный ландшафт: концептуальные подходы, проблемы сохранения и перспективы изучения // Вестник Тюменского государственного университета. Социально-экономические и правовые исследования. 2009. № 7. С. 98-100.

5. Калуиков B.H. Схематизация культурного ландшафта // Культурный ландшафт: Теоретические и региональные исследования / отв. ред. В.Н. Калуцков, Т.М. Красовская. М.: Изд-во Московского ун-та, 2013. $172 \mathrm{c}$.

6. Андреев А.А. Опыт культурно-ландшафтного районирования России // Псковский регионол. журнал. 2012. № 13. С. 12-25.

7. Заруикий С.A. Рекреационные ресурсы культурно-ландшафтных микрорайонов Барановичского административного района Брестской области / С.А. Заруцкий, А.В. Грибко // Мониторинг окружающей среды: сб. материалов II Международной науч.-практ. конф., Брест, 2527 сентября 2013 г.: в 2 ч. / Брест. гос. ун-т им. А.С. Пушкина; редкол: И.В. Абрамова. Брест: БрГУ, 2013. С. 35-37.

8. Исаченко А.Г. Принципы историко-географического районирования (на примере Северо-Запада Европейской России) // Известия Русского географического общества. 2013. Т. 145, вып. 1. С. 3-20.

9. Стрелеикий B.H. Культурный регионализм: сущность понятия, проблемы изучения и система индикаторов // Псковский регионол. журнал. 2012. № 14. С. 9-21.

10. Манаков А.Г. Туристские районы мира. География культурного наследия. Псков: ПГПУ, 2011.320 c.

11. Бусько B.Н. Они были первыми академиками-экономистами Беларуси / под ред. П.Г. Никитенко. Минск: Право и экономика, 2001. 72 с.

12. Шарухо И.Н. Проблемы культурно-географического районирования мира // Магілеўскі мерыдыян. 2013. № 1-2 (20-21). Т. 13, вып. 1-2. С. 73-79.

13. Никогосян А.П. Экономические аспекты въездного туризма в страны Восточной Европы: автореф. дис. ... канд. экон. наук. СПб., 2000. 26 с.

14. Набедрик B.A. География лечебного туризма в Европе: Модели развития и трансформационные процессы: автореф. дис. ... канд. геогр. наук. М., 2005. 24 с.

15. Hall D. Branding and national identity: the case of Central and Eastern Europe // Destination Branding: Creating the Unique Destination Proposition / ed. by Nigel Morgan, Annette Pritchard, Roger Pride. Oxford: Butterworth-Heinemann, 2014. P. 111-127.

16. Шувалова О.В., Ардашева В.Н. Особенности современного туризма в странах Восточной Европы // Сборники конференций НИЦ «Социосфера». 2013. № 4. С. 54-59.

17. Национальный статистический комитет Республики Беларусь [Электронный ресурс]. URL: http://www.belstat.gov.by (дата обращения: 22.10.2016).

Khariton Viktotia V. Grodno State University n.a. Y. Kupaly (Republic Belarus, Grodno) E-mail: vvhariton@mail.ru Tomsk State University Journal of Cultural Studies and Art History, 2018, 29, pp. 156-162. DOI: $10.17223 / 22220836 / 29 / 14$

TO THE QUESTION OF THE REGIONAL EASTERN EUROPE AS A TOURISTIC REGION AT THE END OF THE XX - THE BEGINNING OF THE XXI CENTURY

Key words: tourism, Eastern Europe, tourist region, cultural and historical approach.

Currently, tourism is one of the largest industries in the world. The tourism industry is very competitive, and tour operators are under increasing pressure. In connection with this trend, close attention is paid to a variety of areas of tourist flows, including in Eastern Europe.

This article is devoted to the generalization of the experience of tourism in the Eastern European region at the present stage of the development of society. The article explores the issues of regionalization of Europe, the specifics of tourism development in the countries of the tourist region of Eastern Europe, as well as the problems of tourism development in this region in the late 20th and early 21 st 
centuries. The article highlights the problem of regionalization of Europe, which today is controversial. Classification of tourist zones of the world, proposed by the WTO, has become very popular. Also in the article are classifications - the system of tourist zoning, proposed by researchers D.D. Dmitrievsky, A.G. Manakov. Among other things, the article examines approaches to the regionalization of the Republic of Belarus, relying on the cultural and geographical division of the world. The analysis shows the prospects for tourism business in Eastern Europe. The Republic of Belarus, as one of the countries of this region, has undoubted tourist potential.

\section{References}

1. World Trade Organization. [Online]. Available from: https://www.wto.org. (Accessed: 16th November 2016).

2. Dmitrievskiy, Yu.D. (2000) Turistskie rayony mira [Touristy areas of the world]. Smolensk: Smolensk State University.

3. Gerasimov, A.S. (2013) Podkhody k issledovaniyu regional'noy identichnosti v otechestvennoy nauke [Approaches to the study of regional identity in Russian science]. Vestnik Pskovskogo gosudarstvennogo universiteta. Seriya "Estestvennye i fiziko-matematicheskie nauki”. 3. pp. 57-63.

4. Ivanova, L.V. (2009) Istoriko-kul'turnyy landshaft: kontseptual'nye podkhody, problemy sokhraneniya i perspektivy izucheniya [Historical and cultural landscape: conceptual approaches, preservation problems and prospects of study]. Vestnik Tyumenskogo gosudarstvennogo universiteta. Sotsial'no-ekonomicheskie i pravovye issledovaniya - Tyumen State University Herald. Social, Economic, and Law Research. 7. pp. 98-100.

5. Kalutskov, V.N. (2013) Skhematizatsiya kul'turnogo landshafta [Planning the cultural landscape]. In: Kalutskov, V.N. \& Krasovskaya, T.M. (eds) Kul'turnyy landshaft: Teoreticheskie $i$ regional'nye issledovaniya [Cultural landscape: Theoretical and regional studies]. Moscow: Moscow State University.

6. Andreev, A.A. (2012) Opyt kul'turno-landshaftnogo rayonirovaniya Rossii [Experience of cultural and landscape zoning in Russia]. Pskovskiy regionologicheskiy zhurnal. 13. pp. 12-25.

7. Zarutskiy, S.A. \& Gribko, A.V. (2013) [Recreational resources of cultural and landscape microdistricts of the Baranovichi administrative district, Brest Region]. Monitoring okruzhayushchey sredy [Environmental Monitoring]. Proc. of the Second International Conference. Brest, September 25-27, 2013. Brest. pp. 35-37. (In Russian).

8. Isachenko, A.G. (2013) Printsipy istoriko-geograficheskogo rayonirovaniya (na primere Severo-Zapada Evropeyskoy Rossii) [Principles of historical and geographical regionalisation (a case study of the North-Russian West of European Russia)]. Izvestiya Russkogo geograficheskogo obshchestva. 145(1). pp. 3-20.

9. Streletskiy, V.N. (2012) Kul'turnyy regionalizm: sushchnost' ponyatiya, problemy izucheniya i sistema indikatorov [Cultural regionalism: the essence of the concept, problems of study and the system of indicators]. Pskovskiy regionologicheskiy zhurnal. 14. pp. 9-21.

10. Manakov, A.G. (2011) Turistskie rayony mira. Geografiya kul'turnogo naslediya [Touristy areas of the world. Geography of Cultural Heritage]. Pskov: Pskov State Pedagogical University.

11. Busko, V.N. (2001) Oni byli pervymi akademikami-ekonomistami Belarusi [They were the first academicians-economists of Belarus]. Minsk: Pravo i ekonomika.

12. Sharukho, I.N. (2013) Problemy kul'turno-geograficheskogo rayonirovaniya mira [Problems of cultural and geographical division of the world]. Magiley̆ski merydyyan. 1-2 (20-21). pp. 73-79.

13. Nikogosyan, A.P. (2000) Ekonomicheskie aspekty v"ezdnogo turizma v strany Vostochnoy Evropy [Economic aspects of inbound tourism to the countries of Eastern Europe]. Abstract of Economy Cand. Diss. St. Petersburg.

14. Nabedrik, V.A. (2005) Geografiya lechebnogo turizma v Evrope: Modeli razvitiya i transformatsionnye protsessy [Geography of therapeutic tourism in Europe: Models of development and transformational processes]. Abstract of Geography Cand. Diss. Moscow.

15. Hall, D. (2014) Branding and national identity: the case of Central and Eastern Europe. In: Morgan, N., Pritchard, A. \& Pride, R. (eds) Destination Branding: Creating the Unique Destination Proposition. Oxford: Butterworth-Heinemann. pp. 111-127.

16. Shuvalova, O.V. \& Ardasheva, V.N. (2013) Osobennosti sovremennogo turizma v stranakh Vostochnoy Evropy [Features of modern tourism in the Eastern European countries]. Sborniki konferentsiy NITs Sotsiosfera. 4. pp. 54-59.

17. National Statistical Committee of the Republic of Belarus. [Online] Available from: http://www.belstat.gov.by. (Accessed: 22nd October 2016). 